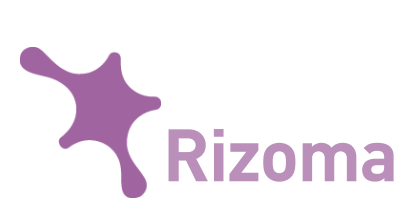

\title{
A reconfiguração das vozes narrativas no jornalismo midiatizado
}

\author{
Demétrio de Azeredo Soster ${ }^{1}$
}

\section{Resumo}

Observa-se, no artigo, a reconfiguraçãodos processos deenunciação,denominados de "vozes narrativas", que se verificam em uma perspectiva de jornalismo midiatizado. Parte-se do pressuposto que a midiatização, ao afetar o jornalismo, provoca transformações também na forma como as enunciações são realizadas no interior dos dispositivos. A mais evidente delas, na análise, é a reconfiguração do papel desempenhado pelo segundo narrador, a partir do esquema proposto por Motta (2013), e a inserção de um quarto narrador, que é formado pelos dispositivos que servem de nós e conexões ao sistema jornalístico. Descreve-se, ainda, parte do percurso do grupo de pesquisa Jornalismo e literatura: narrativas reconfiguradas, que analisa as referidas transformações nos livros-reportagem e biografias do jornalista e escritor Fernando Morais.

Palavras-chave: jornalismo midiatizado; midiatização; narrativas; narrativas reconfiguradas; literatura

\section{Resumen}

Se observa, en el artículo, la reconfiguración de los procesos de enunciación, de-nominados de "voces narrativas", que se verifican en una perspectiva de periodismo mediatizado. Se parte del presupuesto que la mediatización, al afec $\neg$ tar el periodismo, provoca transformaciones también en la forma como las enun $\neg$ ciaciones son realizadas en el interior de los dispositivos. La más evidente de ellas, en el análisis, es la reconfiguración del papel desempeñado por el segundo narrador, a partir del esquema propuesto por Motta (2013), y la inserción de un cuarto narrador, que es formado por los dispositivos que sirven de nudos y conexiones al sistema periodístico. Se describe, aún, parte del recorrido del grupo de pesquisa Jornalismo e literatura: narrativas reconfiguradas, que analiza las referidas transformaciones en los libros-reportaje y biografías del periodista y escritor Fernando Morais.

Palabras clave: Periodismo Mediatizado; Mediatización; Narrativas; Narrativas reajustadas; Literatura.

\author{
${ }^{1}$ Doutor em Comunicação pela \\ Unisinos, Chefe do departamento \\ de Comunicação Social e professor- \\ -pesquisador do PPG Letras da \\ Universidade de Santa Cruz do \\ Sul (Unisc). Artigo originalmente \\ apresen-tado no $12^{\circ}$ encontro da \\ Associação Brasileira de Pesquisa- \\ dores de Jornalismo (12 ${ }^{\circ}$ SBPJor), \\ em novem-bro de 2014, em Santa \\ Cruz do Sul (RS). dsoster@uol. \\ com.br
}



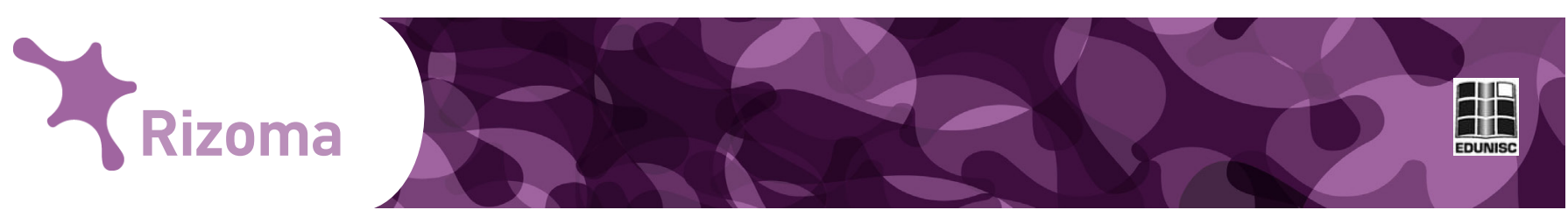

\begin{abstract}
It is observed in the article, the reconfiguration of enunciation processes, called "narrative voices", which is verified upon the mediatic journalism perspective. It starts from the assumption that the mediatization, by affecting journalism, causes changes in the way utterances are held inside the devices as well. The most evident, according to this analysis, is the reconfiguration of the role played by the second narrator, from the scheme proposed by Motta (2013), and the inclusion of a fourth narrator, which is formed by devices that serve as nodes and connections to the journalistic system. It is also presented a part of the path from the research group: Journalism and literature: reconfigured narratives, which analyzes such changes in the reportage books and biographies written by the journalist and writer Fernando Morais.
\end{abstract}

Keywords: mediatized journalism; Mediatization; narratives; reconfigured narratives; literature.

Este artigo, parte integrante do percurso de pesquisa que busca compreender as complexificações ocorridas no jornalismo em uma determinada ambiência, de profunda imersão tecnológica, observa reconfigurações de ordem processual na emissão de vozes narrativas em uma perspectiva de jornalismo midiatizado. Ou seja, do ponto de vista da prática jornalística cujos dispositivos, ao se estabelecerem como vetores de midiatização, são afetados pela processualidade desta, midiatizando-se, redesenhando, uma vez mais, uma geografia com pelo menos 300 anos de percurso evolutivo. Redefinindo, desta maneira, aquilo que Silverstone (2002), a partir de Isaiah Berlin, chamou de "textura geral da experiência", que passa a ser pensada, com cada vez mais intensidade, a partir do papel exercido pela mídia na sociedade.

A atenção recairá especificamente sobre a dialogia, característica de natureza sistêmica-processual do jornalismo midiatizado, que se identifica como tal quando dois sistemas estabelecem relações por meio do acoplamento estrutural, transformando e sendo transformados neste movimento (SOSTER, 2012, 2013), como veremos mais adiante. Vinculamos, portanto, o conceito de dialogia desde agora a uma perspectiva antes sistêmica, nos moldes de Nicklas Luhmann (2009), que linguística, ainda que, em sua processualidade, também provoque afetações no nível dos enunciados. A hipótese que nos move é que, em decorrência do acoplamento estrutural entre os sistemas jornalístico e o literário, objeto de nossa atenção, observa-se uma reconfiguração na emissão das vozes narrativas, o que exige gramática específica de reconhecimento. Analisaremos especificamente o sistema jornalístico, deixando as afetações sobre o sistema literário para um segundo momento.

Nosso caminho se iniciará pela contextualização teórico-metodológica do cenário em análise, seguirá pela descrição de um modelo analítico possí- 

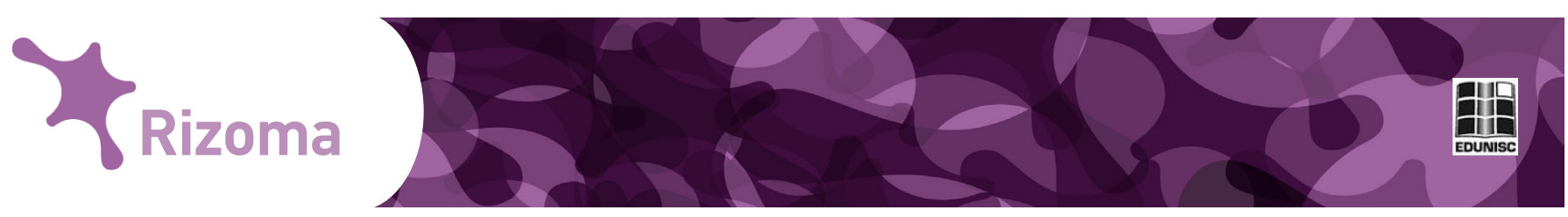

vel para se compreender a referida processualidade, analisará alguns achados realizados, até aqui, pelo grupo de pesquisas Jornalismo e literatura: narrativas reconfiguradas, que coordenamos, e encaminhará, então, para as considerações interpretativas.

O recorte analítico se dará sobre a obra do jornalista Fernando Morais, tanto no que tem de livros-reportagem como de biográfica, em particular os livros-reportagem Transamazônica (Brasiliense, 1970), A Ilha (Alfa-Omega, 1984), Corações sujos (Companhia das Letras, 2011), Cem quilos de ouro (Companhia das Letras 2003) e, finalmente, Os últimos soldados da Guerra Fria (Companhia das Letras, 2011). Quanto às biografias, Olga (Alfa-Omega, 1986), Chatô (Cia das Letras, 1995) e O Mago (Planeta do Brasil, 2008).

\section{Cenários reconfigurados}

\subsection{Perspectiva sistêmica}

Uma estratégia possível para compreender as referidas reconfigurações das vozes narrativas no cenário proposto é pelo viés, de um lado, da análise da processualidade sistêmica, que permite, em nossa perspectiva, identificá-la como tal, enquanto que, de outro, pela narratologia. No primeiro caso, sistêmico, é preciso observar que a natureza das operações de um sistema, sejam eles orgânicos, psíquicos ou sociais, são autorreferenciais, ou seja, voltadas para a manutenção do próprio sistemas. Por este viés, sistemas autorreferentes, ou autorreferenciais, são sistemas que conseguem realizar operações a) consigo mesmo e b) diferenciar essa relações frente a seu entorno (NEVES, RODRIGUES, 2012, p. 20).

Significa, em palavras mais simples, que o objetivo primeiro de todo sistema é sua própria manutenção, o que se dá por meio da geração de diferenças que gerem diferenças. Essa geração de diferenças é o que permite, ao sistema, ser reconhecido como tal. Ocorre que não podemos pensar os sistemas ou produção de diferenças, sem considerar, na análise, o ambiente em que se inserem, e, neste, os demais sistemas. A autorreferência se produz quando algo no ambiente, ou nos demais sistemas, "chama atenção" do sistema - em nosso caso, jornalístico. Ao fazê-lo, é absorvido pelo sistema sob a forma de informação. Chamamos este processo - o "chamar atenção" -, na nomenclatura dos sistemas, de irritação.

(...) as irritações sempre estão referidas (e orientadas) às estruturas e, no âmbito dos acontecimentos de sentido, elas estão voltadas para as expectativas possíveis, que já trazem impresso um sentido de avaliação: somente com isso pode-se obter informação. Dessas expectativas possíveis, surge uma perturbação, uma irritação, que se torna atual no sistema, e faz com que a autopoeiesis da operação do sistema reaja mediante identificação ou rejeição: no momento em que surge um odor cheirando a queimado, não se sabe se são as batatas ou algo que se incendeia na casa, mas, em todo o caso, sempre há uma interpretação limitada da percepção de um odor inabitual de queimado. (...) Irritação (perturbação, estimulação) significa, portanto, desenvolver o processamento de informação que 


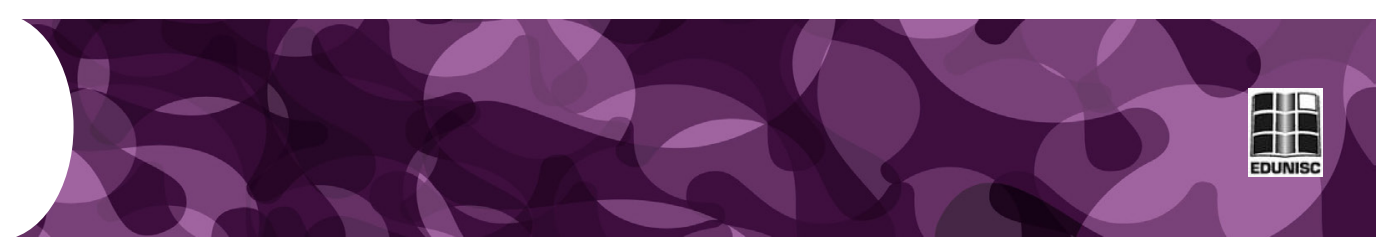

só pode se realizar dentro do sistema. (LUHMANN, 2009, p. 138-139).

A informação produzida pelo viés da irritação, uma vez no sistema, passa por um processo de redução de complexidade, cujo objetivo é tornar possíveis as operações no interior do sistema. É o que ocorre, por exemplo, quando um acontecimento, à revelia de sua natureza, desperta a atenção do sistema jornalístico, que é formado, em termos de dispositivos, por jornais, revistas, sites, blogs, televisões, rádios e, mais recentemente, livros. Amalgamados em rede, por meio da web, operam como nós e conexões da mesma e dão forma ao sistema como um todo.

Este acontecimento - um ônibus que cai de uma ponte, por exemplo, pelos motivos os mais diversos - será introduzido no interior do sistema por um dos nós ou conexões dos mesmos (dispositivos) e será transformado em notícia (ou qualquer outro formato de texto, dentre as categorias e gêneros conhecidos). "Transformá-lo" em relato jornalístico implica, sobretudo, em torná-lo compreensível, linear, de tal maneira que não resultem dúvidas a respeito dele, quando então será veiculado.

Ocorre que, antes mesmo que ser "devolvido" ao ambiente, o acontecimento em questão já "irrita" o sistema jornalístico, por meio de dispositivos como sites, blogs, emissões de rádio, tevê etc. Quando isso ocorre, o movimento que se verificou no dispositivo jornal tende a ocorrer em todo o sistema, transformando, em um primeiro momento, o próprio sistema, de tal forma que, ao observador externo, o acontecimento passa a existir principalmente como um algo antes próprio do sistema que no mundo se realizando. É dizer, em outras palavras, que o acidente em questão passará a existir principalmente a partir de uma lógica midiática.

É preciso dizer que, em muitos casos, depois de ser devolvido ao ambiente, o acontecimento, agora de natureza jornalística, pode ser absorvido novamente pelo sistema, e devolvido uma vez mais ao ambiente (SOSTER, 2009), mas deixaremos esta discussão para um segundo momento, sob o risco de desviarmos o foco da atenção. Mais relevante, neste momento, é observar que também os sistemas dialogam entre sí, em primeiro lugar pelo viés da irritação, que é sempre autoproduzida, ou seja, parte do interior dos próprios sistemas (LUHMANN, 2009), e, em seguida, pelo acoplamento estrutural. Sempre que o fazem, transformam a ambos neste processo.

No caso específico dos diálogos existentes entre o jornalismo e a literatura, objeto de nosso interesse, e frisando que este tipo de acoplamento sistêmico se verifica desde há muito entre os dois campos do conhecimento, podemos constatar o diálogo entre os sistemas à medida que jornais diários como Zero Hora, por exemplo (PICCININ, SOSTER, 2014), se valem cada vez mais de lógicas discursivas próprias da literatura para oferecer sentidos e estabelecer relações.

$\mathrm{O}$ mesmo ocorre com a revista Piauí, por exemplo, à medida que, em muitos de seus relatos, a narrativa é, antes, literária que jornalística; e provoca, em suas operações, transformações as mais diversas (SOSTER, 2011). Do ponto de vista literário, sob outro ângulo, a afetação se torna perceptível na literatura quando esta passa a se valer de lógicas antes midiáticas que literárias em seus relatos, a título de comparação. 


\section{$t^{*}$}

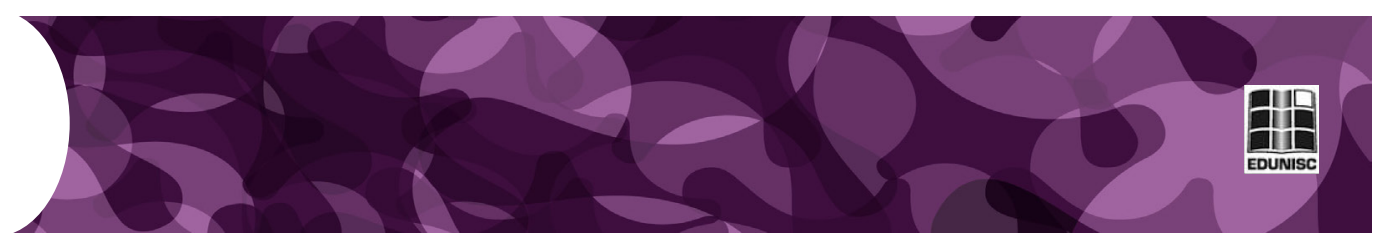

\subsection{Narratologia}

Do ponto de vista da narratologia, estamos falando de uma perspectiva que observa a narrativa como modo de representação tanto do que é como do que não é literário.

Concebendo a narrativa em uma perspectiva organicista, a narratologia procura, pois, descrever de forma sistemática os códigos que estruturam a narrativa, os signos que esses códigos compreendem, ocupando-se, pois, de um modo geral, da dinâmica de produtividade que preside à enunciação dos textos narrativos. (...) A narratologia, ao contemplar prioritariamente as propriedades modais da narrativa, não privilegia exclusivamente os textos literários, nem se restringe aos textos narrativos verbais; ela visa também práticas narrativas como cinema, a história em quadrinhos ou a narrativa de imprensa (...)". (LOPES, REIS, 1988, p. 79-80).

Inserido neste contexto, há muitas formas de se compreender a narratologia, e a visada estrutural, ou seja, pelo viés da análise das partes que compõem o texto - personagem, narrador, narratário etc. - é, talvez, a mais visível delas. Por este viés, no rastro de autores como Todorov e Barthes (2011), para ficarmos em dois dos principais, ao analisarmos a estrutura que compõe os textos chegamos ao significado mais largo do mesmo. A outra perspectiva, na qual Motta (2013) se filia, e com a qual dialogamos mais estreitamente, observa a narratologia como

(...) estudo dos processos de relações humanas que produzem sentido através de expressões narrativas, sejam elas factuais (jornalismo, história, biografias etc.) ou ficcionais (romances, contos, cinema, telenovelas, mitos). Procura entender como os sujeitos sociais constroem intersubjetivamente seus significados pela apreensão, representação e expressão narrativa da realidade. A produção cultural de sentidos é, portanto, um fator prévio que implica e engloba essa nova narratologia. (MOTTA, 2013, p.79).

Considerando, ainda de acordo com Motta (2013), que as narrações têm um lugar de destaque nesta perspectiva, em elas sendo observadas, alcança-se, quem sabe, instâncias mais largas de significação. A compreensão, por outro lado, de que processos de enunciação têm nos narradores os seus agentes, vistos aqui como - “(...) seres capazes de expressar sentimentos e ações." (Motta, 2013, p. 214) - delimita ainda mais o ângulo de nosso olhar, ainda que exija instrumental analítico apropriado. Vamos chamar estas formas de expressão de "vozes narrativas", ou seja, as emissões realizadas pelos narradores.

Neste sentido, e a partir do modelo de análise de Genette (1988) para análise de domínio das vozes narrativas, Motta desenvolveu um diagrama por meio do qual pudesse observar os níveis de poder das narrações jornalísticas. Neles, como observado em momentos anteriores (SOSTER, 2014, 2014a), verificamos três instâncias narrativas, ou três narradores, por meio das quais as enunciações têm lugar, abaixo descritas: 

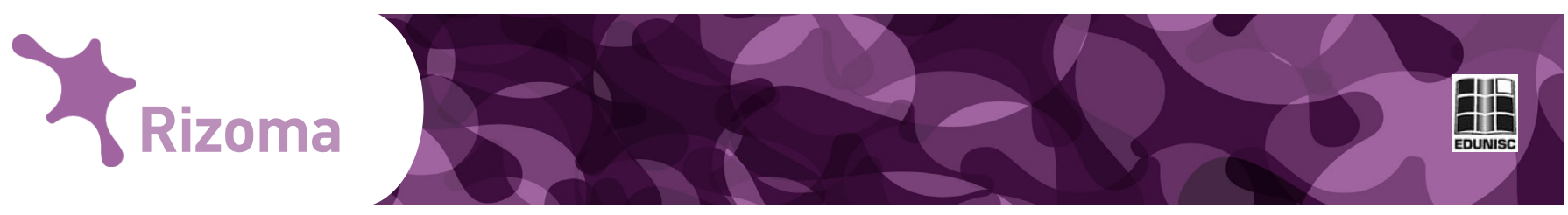

1 Primeiro narrador (narrador-jornal, extradiegético - fora da história). É a organização jornalística, que viabiliza, por meio de seus agentes, o dispositivo jornal (e os demais dispositivos dessa natureza).

2 Segundo narrador (narrador-jornalista, intradiegético - dentro da história). Como o nome sugere, é o jornalista, “(...) a voz que enuncia propriamente a narração, organiza e costura a tessitura da intriga, dispõe as ações, conflitos, personagens e cenas." (Motta, 2013, p. 228)

3 Terceiro narrador (narrador-personagem, intradiegético - dentro da história). São as fontes, ou personagens, das notícias.

Graficamente, temos a seguinte situação:

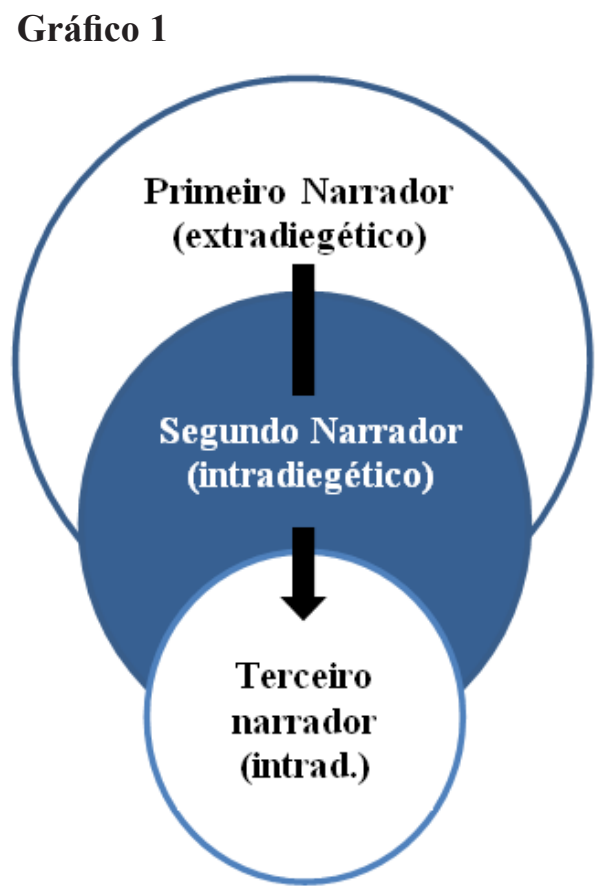

Fonte: elaboração dos autores

Antes de prosseguirmos, há algo a ser dito, ainda, em relação ao modelo analítico de Motta (2013). Observe-se que ele foi desenvolvido, em sua origem, para análise de notícias veiculadas em jornais. Ou seja, por organizações que dialogam com seu público-alvo por meio de dispositivos cuja circulação é diária, semanal etc.; sobretudo, que tem na periodicidade um elemento determinante para sua forma de ser. E que são geridos, em termos de processos, por uma hierarquia produtiva composta, de um lado, por organizações, que intereferem hierarquicamente nas demais instâncias narrativas, caso dos repórteres, e assim sucessivamente. A interferência, observe-se, é mútua; mas tende a ser mais incisiva, e determinante, do primeiro para o terceiro narradores.

Isso posto, algumas perguntas se fazem necessárias.

A primeira, e mais evidente, consideramos o que foi dito anteriormente, é o que ocorre em modelos de relatos jornalísticos em que a periodicidade não 

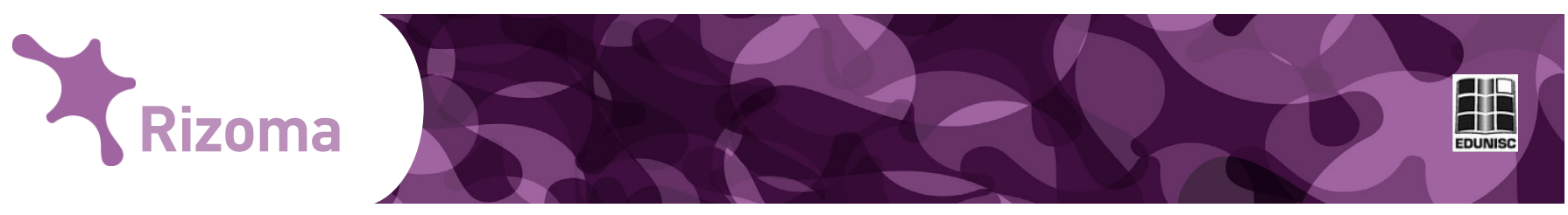

interfere em sua forma de ser, caso dos livros-reportagem e das biografias de natureza jornalística? Nestes casos, ainda que o primeiro-narrador (organização) se faça igualmente presente, a hierarquia na emissão de vozes parece se reconfigurar. Pode-se pensar, ainda, que a "entrada" destes modelos de relatos no sistema jornalístico acabe por reconfigurar o próprio sistema, inserindo nele novas vozes enunciativas.

Estas e outras questões vêm fazendo parte do percurso de pesquisa do grupo Jornalismo e literatura: narrativas reconfiguradas ${ }^{2}$, que estuda estas complexificações. Com base na análise da obra de Fernando Morais, observou-se que livros-reportagem e biografias de natureza jornalística, por exemplo, são, de um lado, jornalismo, mas, no entanto, suas lógicas discursivas são substancialmente distintas dos demais veículos, por exemplo. A constatação sugere que, para se pensar estes modelos, são necessárias gramáticas específicas (SOSTER, 2013a), sob o risco de não serem compreendidos em sua essência.

\section{Vozes reconfiguradas}

Se admitirmos, portanto, que os livros-reportagem, e as biografias de natureza jornalística, se inserem no sistema jornalístico em decorrência a) do acoplamento estrutural entre sistema jornalístico e sistema literário e que, por isso, b) verificamos a complexificação de toda uma geografia enunciativa, então precisamos, para melhor compreendê-la, de um esquema analítico que nos permita observá-la melhor em sua processualidade. Antes disso, as necessárias delimitações conceituais.

Por livro-reportagem vamos compreender, doravante, como sendo um “(...) veículo de comunicação impressa não-periódico que apresenta reportagens em grau de amplitude superior ao tratamento costumeiro nos meios jornalísticos periódicos" (LIMA, 2009, p. 26). Quanto às biografias de natureza jornalística, Lima (2009) sustenta serem, ao lado do livro-reportagem perfil, “(...) uma variante dessa modalidade (...)”, ou seja, um modelo que se estabelece "(...) quando um jornalista centra suas baterias mais em torno da vida, do passado, da carreira (...) normalmente dando mais destaque ao presente" (LIMA, 2009, p.45) de alguém.

Retornando ao esquema analítico, um caminho possível, a partir dos passos já realizados por Genette (1988) e Motta (2013), está sendo desenvolvido pelo grupo de pesquisas Jornalismo e literatura: narrativas reconfiguradas. Com base nas percepções acima descritas, qual seja, que há modelos, e, neles, gêneros com tempos diferenciados de narrativas jornalísticas - caso dos livros-reportagem e das biografias de natureza jornalística -, e, considerando, ainda, que estes integram, como nós, ou conexões, o sistema jornalístico ao lado dos demais dispositivos (jornais, revistas, rádios, televisões e sites, por exemplo), podemos pensar que esta diferença se estabelece também na emissão das vozes narrativas.

Vejamos o que ocorre, por exemplo, com os três narradores já conheci- 

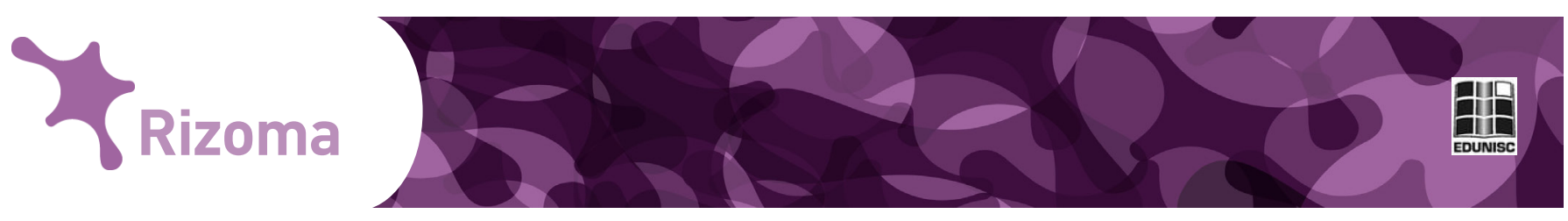

dos: primeiro, segundo e terceiro. Como não há, no caso dos livros, exigência de processos produtivos repetitivos, caso do que ocorre com um jornal diário, em decorrência da periodicidade, que não existe usualmente no caso dos livros, podemos pensar que a voz do segundo narrador (jornalista) ganha uma relevância igual ou superior ao primeiro narrador (organização), e que ambos seguem falando "mais alto" que o terceiro narrador. O esquema abaixo ilustra o que estamos afirmando:

\section{Gráfico 2}

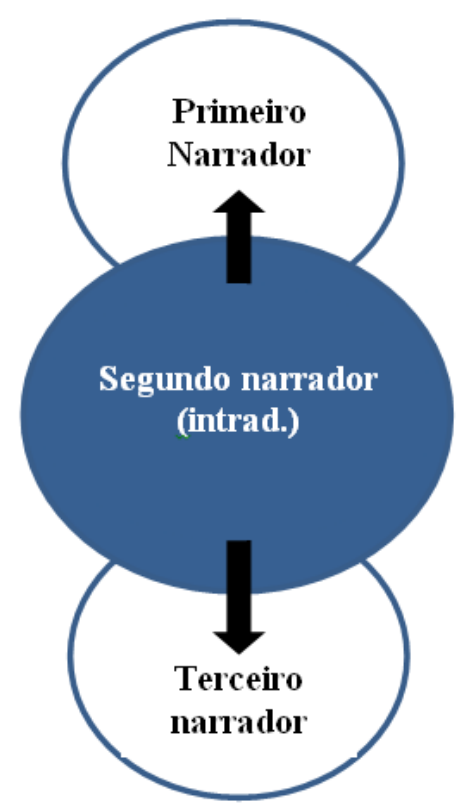

Fonte: elaboração dos autores

Devemos levar em conta, ainda, que, a processualidade acima descrita, mesmo reconfigurada na relação com o modelo original, diz respeito, principalmente, ao dispositivo. Ou seja, que tanto o primeiro, como o segundo e o terceiro narradores são vistos, por quem os observa, na perspectiva das enunciações realizadas nos livros-reportagem e nas biografias de natureza jornalística. A afirmação diz respeito, portanto, também ao primeiro narrador, extradiegético, à medida que sua identificação se dá pelas marcas existentes no livro (capa, índices, referências etc.).

Mas, se considerarmos, como dissemos, que também os livros-reportagem e as biografias se inserem no sistema jornalístico, podemos admitir a presença de um quarto narrador, formado, de um lado, a) pela presença dos livros no sistema jornalístico como nós e conexões deste, e, de outro, b) pelo conjunto que se forma a partir da reconfiguração do próprio sistema. Considera-se, aqui, portanto, que a entrada dos livros como elementos constituintes do sistema jornalístico afeta tanto os livros como o próprio sistema. A questão da temporalidade - os livros sem exigências quanto à periodicidade; os impressos, usualmente diários, semanais, mensais; os eletrônicos, via de regra imediatos - não interfere nos fluxos informativos do sistema, haja 

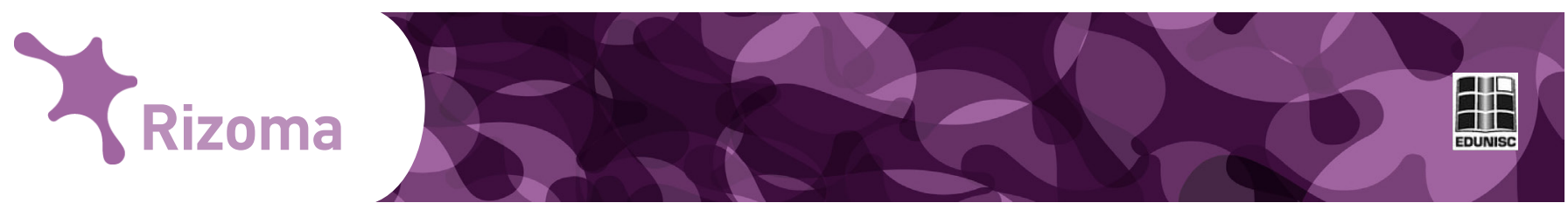

vista que estes são, antes, complexos que lineares, e não possuem, portanto, lógicas previsíveis.

Pensar o sistema como um quarto narrador, extradiegético, implica, ainda, em observá-lo como enunciador, ou seja, detentor de uma voz narrativa. A emissão, neste caso, não se dá de forma direta, a exemplo do que ocorre com o segundo narrador, por exemplo, mas por uma simbiose muito sutil que permite, ao fim e ao cabo, identificarmos o sistema como tal. Tem a ver com marcas, símbolos, gramáticas, regras, estatutos, normas operacionais etc, em uma perspectiva simbiótica. Deixaremos essa reflexão, a respeito da "forma" do sistema, para outro momento.

Optemos por observar, em um primeiro momento visualmente, como se dão os diálogos entre o sistema e o (s) dispositivo (s), considerando o sistema como quarto narrador.

\section{Gráfico 3}

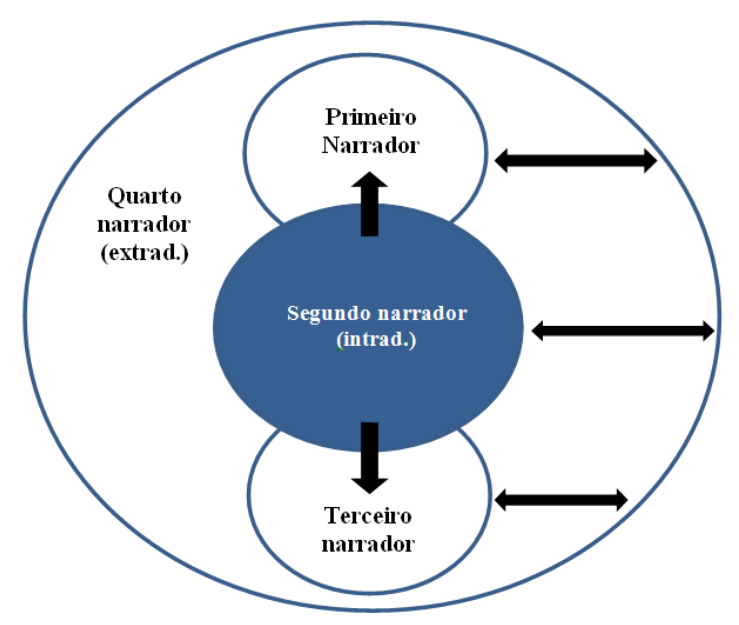

Fonte: elaboração dos autores

Por esta perspectiva, o segundo narrador mantém sua centralidade operacional. Note-se, contudo, que tanto ele como o primeiro e o segundo narradores sofrem interferências do quarto narrador, que igualmente dialoga com seus pares, sendo interferido por estes. A mudança mais imediata que se observa, aqui, é que a centralidade operacional do segundo narrador não afeta o quarto narrador da mesma forma que o faz com o primeiro e o terceiro.

Tem-se, dessa forma, um equilíbrio no processo de enunciação, uma simbiose: o segundo narrador, ao se posicionar como tal, conduz o processo de constituição identitária do dispositivo, permitindo que o mesmo obtenha as credenciais necessárias para se inserir no sistema jornalístico. O sistema, por meio de suas operações, viabiliza não apenas a permanência do dispositivo como um de seus nós mas também sua própria existência enquanto sistema.

\section{Fernando Morais}

A processualidade acima, como dissemos, foi desenvolvida a partir das pesquisas realizadas pelo grupo Jornalismo e literatura: narrativas recon- 

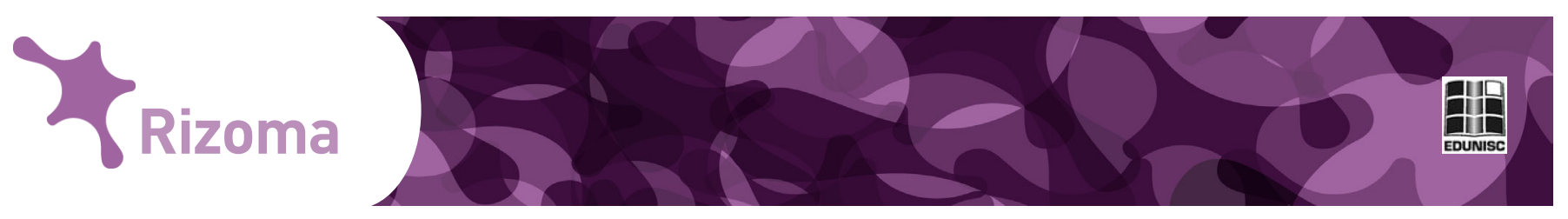

figuradas, tendo como pano de fundo a obra de Fernando Morais, tanto no que tem de livro-reportagem como no que toca às biografias de natureza jornalista, o que sintetizaremos a seguir. Em um primeiro momento (SOSTER at al, 2013), perguntou-se a respeito do papel desempenhado pelos gêneros jornalístico na narrativa não-biográfica de Morais.

Duas conclusões emergiram dessa primeira questão, como base no material analisado: a) que não é possível compartimentalizar os relatos nesta ou naquela categoria, haja vista que, neles, são encontrados excertos de todos os gêneros propostos pela categorização de José Marques de Melo (2000) e b) a presença das categorias interpretativo, diversional, opinativo e informativo (utilitário não foi encontrada) indicava a existência de camadas mais profundas de significação, o que exigia, a um tempo, visadas estruturais, enquanto que, de outro, fenomenológicas, nos moldes descritos.

Uma conclusão parcial considerava que a polifonia de gêneros representava, na verdade, estratégia discursiva por meio da qual o segundo narrador, já reconfigurado na relação com a proposição de Motta (2013), mostrava-se como detentor de uma voz narrativa capaz de influenciar tanto o primeiro como o segundo narradores. Sobretudo, que as categorias e gêneros operavam, antes, como indexadores de camadas mais profundas de significação, o que foi observado com mais atenção em 2014.

Foi necessário, para isso, considerar que as categorias, os gêneros e as estruturas existentes em determinados modelos de narrativas, caso dos livros-reportagem, eram camadas superpostas de significação. Compreendê-las implica observar, também, os jogos de poder existentes entre os narradores envolvidos nos mais diversos processos de enunciação por meio de suas vozes narrativas. (Soster at al, 2014, p. 11).

A passagem de nível analítico conduziu a pesquisa a novo esforço conceitual, com o que chegamos à reconfiguração anteriormente descrita, cujos resultados se encontram descritos no livro Narrativas comunicacionais complexificadas 2 - a forma, a ser lançado em novembro (Edunisc, 2014a). No capítulo Vozes narrativas reconfiguradas nas biografias de natureza jornalística, os livros trabalhados com este perfil foram O Mago (2008), Chatô: o rei do Brasil (1995) e Olga (1986). Na toca dos leões (2004) e Montenegro (2006). Por meio da aplicação, neles, de tabela que nos permitisse identificar os narradores, e, nelas, as vozes narrativas, observamos não apenas a reconfiguração do segundo narrador em modelos de textos como estes, como, também, a emergência de uma quarta voz narrativa, personificada pela entrada dos livros no sistema jornalístico.

Quanto aos motivos, basicamente porque, como já havíamos inferido anteriormente (SOSTER, 2009), os dispositivos repetem, em seu interior, as mesmas lógicas operacionais do sistema em que se inserem, e a autoreferencialidade é a parte mais visível deste processo. Este papel, na amostra descrita anteriormente, é exercido pelo segundo narrador, em um diálogo muito estreito com os demais níveis narrativos, sejam intra ou extradiegéticos. É ele, ao fim e ao cabo, quem cuida que os livros-reportagem, ou as biografias, 

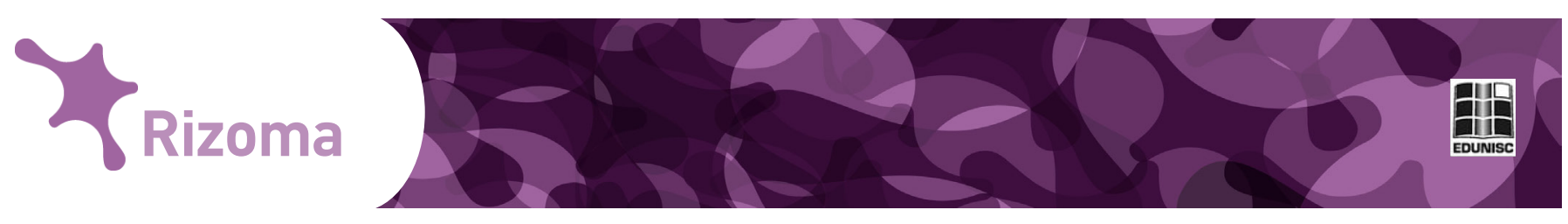

sejam partes integrantes, do ponto de vista identitário, do sistema jornalístico, e este movimento permite que eles, os livros, passem a fazer parte do sistema como membros constituintes deste.

\section{Considerações interpretativas}

Quer nos parecer que a hipótese inicial, qual seja, que, em decorrência do acoplamento estrutural entre os sistemas jornalístico e o literário, observa-se uma reconfiguração na emissão das vozes narrativas, encontra abrigo na análise que realizamos até aqui. Em particular quando diz respeito a determinados formatos de narrativa, caso dos livros-reportagem, presos a temporalidades diferenciadas, na comparação com jornais e revistas, por exemplo. Nestes casos, conforme observamos, tem-se a potencialização de determinada forma de dizer - a quem chamamos de "segundo narrador" -, que passa a exercer influência diferenciada sobre o primeiro e o terceiro narradores. Mas também porque faz emergir um quarto narrador, formado pelo sistema jornalístico, que requer atenção especial de nossa parte.

Este quarto narrador, já a partir de sua "forma" - ele é identificado como um sistema, e não apenas como um dos dispositivos que compõem o sistema - interage com os demais extratos narrativos antes de forma rizomática que axiomática; sem, portanto, centralidades operacionais. Em termos mais simples, não se encontra escrito em uma página, impresso em uma capa ou disposto, na forma de índice onomástico, ao fim de uma publicação: ele é o livro-reportagem, ou a biografia, antes na relação com os jornais, revistas, televisões, rádios, sites etc. que em sua materialidade. Sozinho, é apenas um dispositivo; na relação com os demais dispositivos, parte de um sistema. O sistema, portanto.

\section{Referências}

BARTHES, Roland, GREIMAS, A.J., BREMOND, Claude, ECO, Umberto, Gritti, Jules, MORIN, Violette, METZ, Christian, TODOROV, Tzvetan, GENETTE, Gérard. Análise Estrutural da Narrativa. 7. ed. Petrópolis: Vozes, 2011

LIMA, Edvaldo Pereira. Páginas ampliadas: o livro-reportagem como extensão do jornalismo e da literatura. Barueri: Manole, 2009.

LUHMANN, Nikklas. Introdução à teoria dos sistemas. Petrópolis. RJ: Vozes, 2009.

MORAIS, Fernando. Corações sujos: a história da Shindo Renmei. São Paulo: Companhia das Letras, 2012. 

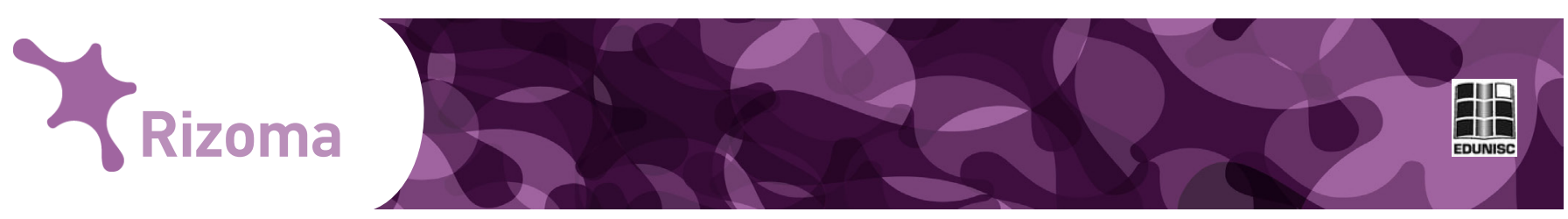

MORAIS, Fernando. Os últimos soldados da guerra fria: a história dos agentes infiltrados por Cuba em organizações de extrema direita nos Estados Unidos. São Paulo: Companhia das Letras, 2011.

MORAIS, Fernando. O Mago. Planeta do Brasil: São Paulo, 2008.

MORAIS, Fernando. Cem quilos de ouro (e outras histórias de um repórter). São Paulo: Companhia das Letras, 2003.

MORAIS, Fernando. Chatô: o rei do Brasil. São Paulo: Companhia das Letras, 1995.

MORAIS, Fernando. Olga. 8. Ed. Alfa-Omega: São Paulo, 1986.

MORAIS, Fernando. A Ilha: um repórter brasileiro no país de Fidel Castro. São Paulo: Alfa-Omega, 1984.

MORAIS, Fernando. Transamazônica. São Paulo: Brasiliense, 1970.

MOTTA, Luiz Gonzaga. Análise crítica da narrativa. Brasília: Editora Universidade de Brasília, 2013.

NEVES, Fabrício Monteiro; RODRIGUES, Leo Peixoto. Niklas Luhmann: a sociedade como sistema. Porto Alegre: Edpucrs, 2012

PICCININ, Fabiana; SOSTER, Demétrio de Azeredo. Narrativas literárias no jornalismo impresso diário: o caso dos jornais Zero Hora e Gazeta do Sul. Brasilian Journalismo Research: Journalismo Theory, Research and Criticism. Estudos e discursos do jornalismo. v. 10, n. 1 PT, p. 128-149. Julho de 2014.

REIS, Carlos; LOPES, Ana Cristina M. Dicionário de teoria da narrativa. São Paulo: Ática, 1988.

SILVERSTONE, Roger. Por que estudar a mídia? São Paulo: Loyola, 2012 SOSTER, Demétrio de Azeredo et al. Além da diversidade de gêneros: o que emerge da complexidade narrativa nos livros-reportagem de Fernando Morais. In:XV Congresso Brasileiro de Ciências da Comunicação da Região Sul, 2014, Palhoça, SC. Anais.

SOSTER, Demétrio de Azeredo. Narrativas reconfiguradas 2 - a forma. Santa Cruz do Sul (RS) - Edunisc, 2014a.

SOSTER, Demétrio de Azeredo. Dialogia e atorização: características do jornalismo midiatizado. In: $10^{\circ}$ Encontro Nacional dos Pesquisadores de Jornalismo, 10., 2013, Brasília. Anais... Brasília, 2013.

SOSTER, Demétrio de Azeredo et al O que dizem os gêneros nas narrativas 

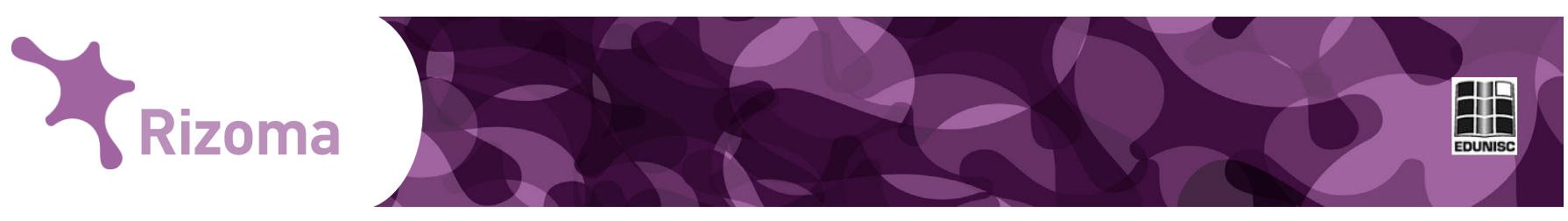

jornalísticas não-biográficas de Fernando Morais. In: XXXVI Congresso Brasileiro de Ciências da Comunicação, 2013-a, Manaus, AM. Anais.

SOSTER, Demétrio de Azeredo. Sistemas, complexidade e dialogias: narrativas jornalísticas reconfiguradas. In: PICCININ, Fabiana; SOSTER, Demétrio de Azeredo. (org.) Narrativas comunicacionais complexificadas. Santa Cruz do Sul: Edunisc, 2012.

SOSTER, Demétrio de Azeredo. A midiatização das narrativas jornalísticas na seção Diário da Revista Piauí. In: $9^{\circ}$ Encontro Nacional dos Pesquisadores de Jornalismo, 2011, Rio de Janeiro. Anais... Rio de Janeiro, 2011.

SOSTER, Demétrio de Azeredo. O jornalismo em novos territórios conceituais: internet, midiatização e a reconfiguração dos sentidos midiáticos. São Leopoldo, 2009. Tese (Doutorado em Comunicação), Programa de Pós-Graduação em Comunicação, Universidade do Vale do Rio dos Sinos, 2009. 